\section{Revista de CIENCIAS AMBIENTALES Tropical Journal of Environmental Sciences}

Revista de Ciencias Ambientales (Trop J Environ Sci)

e-ISSN: 2215-3896

(Julio-Diciembre, 2019) . Vol 53(2): 47-59

DOI: https://doi.org/10.15359/rca.53-2.3

Open Access: www.revistas.una.ac.cr/ambientales e-mail: revista.ambientales@una.ac.cr Rojas-Vargas A. y Hine-Gómez A.

\title{
Micropropagación de clones superiores de caoba (Swietenia macrophylla King) a partir de segmentos nodales
}

\author{
Micropropagation of Superior Clones of Mahogany (Swietenia macrophylla King) \\ from Nodal Segments
}

Alejandra Rojas-Vargas ${ }^{a}$ y Ana Hine-Gómez ${ }^{b}$

[Recibido: 13 de diciembre 2018, Aceptado: 21 de marzo 2019, Corregido: 15 de mayo 2019, Publicado: 1 de julio 2019]

\section{Resumen}

La caoba es la especie forestal nativa económicamente más importante en Latinoamérica, se encuentra en el Apéndice II de CITES, debido a que registra un elevado índice de explotación, producto de la alta extracción sufrida a lo largo de décadas. El objetivo de esta investigación fue desarrollar un protocolo para el establecimiento in vitro de 2 clones (33 y 80), pertenecientes a un programa de mejoramiento genético forestal. Se lograron establecer segmentos nodales de los clones 83 y 33 en condiciones in vitro, al emplear hipoclorito de calcio al $15 \%$ con un tiempo de exposición de 20 minutos. El mejor medio de cultivo para el establecimiento in vitro de los nudos fue el MS complementado con $3 \%$ de sacarosa, $0.016 \mathrm{~g} / 1$ de agrimicin y benlate, obteniéndose un $55 \%$ de nudos establecidos a los 16 días de cultivo. En ambos clones se evaluó el efecto de 5 concentraciones de 6-Bencilaminopurina (6-BAP) $\left(0.0,0.44,0.88,1.33,1.77\right.$ y $\left.2.21 \mu \mathrm{M} \mathrm{L}^{-1}\right)$ sobre la brotación. Se obtuvo en promedio un brote por explante en los 5 tratamientos evaluados. No se observaron diferencias estadísticas significativas.

Palabras clave: bencilaminopurina; cultivo in vitro; especie forestal; nudos; programa mejoramiento genético.

\section{Abstract}

Mahogany is the most economically important native forest species in Latin America. It is listed in Appendix II of CITES because it has a high exploitation rate due to decades of high extraction rates. The objective of this research was to develop a protocol for the in vitro establishment of two clones ( 33 and 80), that belong to a forest genetic improvement program. Nodal segments of clones 83 and 33 were established under in vitro conditions using $15 \%$ calcium hypochlorite with an exposure time of 20 minutes. The best culture medium for in vitro establishment of the nodes was MS supplemented with $3 \%$ sucrose, $0.016 \mathrm{~g} / \mathrm{L}$ of agrimycin and benlate, whose use resulted in establishment in $55 \%$ of nodes after 16 days of culture. In both clones, the effect of five concentrations of 6-Benzylaminopurine (6-BAP) $(0.0,0.44,0.88,1.33,1.77$, and $2.21 \mu \mathrm{M} \mathrm{L}-1)$ on sprouting was evaluated. On average, one sprout per explant was obtained in the 5 treatments evaluated. No significant statistical differences were observed.

Keywords: Benzylaminopurine; forestry species; genetic improvement program; in vitro cultivation; nodal segments.

a Investigadora y docente del Instituto de Investigación y Servicios Forestales, Universidad Nacional (UNA), Costa Rica; alejandra.rojas. vargas@una.ac.cr, https://orcid.org/0000-0003-4874-2161

b Investigadora y docente del Instituto de Investigación y Servicios Forestales, Universidad Nacional (UNA), Costa Rica, ana.hine.gomez@ una.ac.cr, https://orcid.org/0000-0002-7226-2275

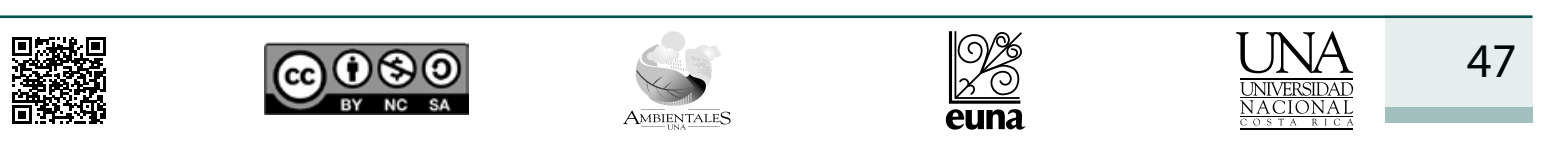




\section{Revista de CIENCIAS AMBIENTALES Tropical Journal of Environmental Sciences}

Revista de Ciencias Ambientales (Trop J Environ Sci) e-ISSN: 2215-3896

(Julio-Diciembre, 2019) . Vol 53(2): 47-59 DOI: https://doi.org/10.15359/rca.53-2.3

Open Access: www.revistas.una.ac.cr/ambientales e-mail: revista.ambientales@una.ac.cr Rojas-Vargas A. y Hine-Gómez A.

\section{Introducción}

Los bosques son una fuente de recursos fitogenéticos valiosos y a pesar de que se han concretado grandes esfuerzos para conservar el medio ambiente, estos no han sido suficientes. En consecuencia, aún existe una sobreexplotación de especies forestales de alto valor económico y ecológico (Wadsworth, 2000). Lo anterior, ha generado la necesidad de establecer plantaciones forestales, con el objetivo de satisfacer la demanda de madera, aumentar la productividad y estabilidad económica del sistema (Martínez et al., 2003).

La caoba tiene una distribución natural en América Tropical desde la Península de Yucatán en México hasta la región Amazónica de Brasil, Perú y Bolivia. Además, presenta una copa estrecha que mantiene sus hojas durante la mayor parte de la estación seca, lo que la hace adecuada para combinarla con cultivos como el café, el cacao, la vainilla y pastizales arbolados. Tiene un rango de distribución amplio y en Costa Rica se puede cultivar desde el nivel del mar hasta los $1300 \mathrm{~m}$ de elevación, tanto en zonas secas como húmedas (Corea, 2012; Maruyama et al., 1997; Schottz et al., 2007). Es una especie forestal nativa de rápido crecimiento, con alto valor y demanda en el en el mercado nacional e internacional y tiene aceptación por parte de los consumidores, es la especie forestal nativa económicamente más importante en Latinoamérica (Corea, 2012).

Es una especie maderable de las más valoradas a nivel mundial por su belleza, ductilidad y durabilidad, se usa en la fabricación de muebles de alta calidad, construcción de botes y carpintería entre otros (Maruyama et al., 1997; Schottz et al., 2007).

Swietenia macrophylla se ubica en la categoría de conservación en peligro crítico según el estudio del estado de la conservación de plantas en Costa Rica 2005, y se encuentra en el Apéndice II de CITES (CITES, 2017). Lo anterior, se debe a que registra un elevado índice de explotación, producto de la alta extracción sufrida a lo largo de décadas, a causa de su apreciada madera, y por su escasez (Estrada et al., 2005). Actualmente, el valor de su madera en el mercado internacional triplica el de especies como la teca, o el cedro y es diez veces mayor que el de especies como la melina, los eucaliptos y los pinos (Corea, 2012).

El rescate de especies forestales de interés comercial es una de las líneas prioritarias del cultivo de tejidos como herramienta básica para apoyar al mejoramiento de árboles élites. La técnica cultivo de tejidos vegetales tiene entre sus ventajas que contribuye a elevar las tasas de multiplicación, y permite que el material generado se utilice en plantaciones forestales (Acosta et al., 2009). En Caoba se han realizado investigaciones utilizando diferentes técnicas dentro de la micropropagación (Barbon et al., 2006; Collado et al., 2004; Carranza et al., 2013). Sin embargo, en la mayoría de artículos científicos consultados sobre el establecimiento in vitro de la especie no utilizaron material vegetativo de clones superiores perteneciente a un programa de mejoramiento genético forestal. Por lo anterior, el objetivo de la investigación fue establecer las bases para la micropropagación in vitro de clones superiores de caoba mediante el estudio del efecto de reguladores de crecimiento sobre la brotación de segmentos nodales.

\begin{tabular}{|c|c|c|c|c|}
\hline 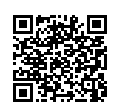 & (c) & $\underset{\text { AMBENENALIES }}{\infty}$ & $\frac{1 \%}{\text { euna }}$ & 48 \\
\hline
\end{tabular}




\section{Revista de CIENCIAS AMBIENTALES Tropical Journal of Environmental Sciences}

Revista de Ciencias Ambientales (Trop J Environ Sci) e-ISSN: 2215-3896

(Julio-Diciembre, 2019) . Vol 53(2): 47-59 DOI: https://doi.org/10.15359/rca.53-2.3 Open Access: www.revistas.una.ac.cr/ambientales e-mail: revista.ambientales@una.ac.cr Rojas-Vargas A. y Hine-Gómez A.

\section{Metodología}

\subsection{Establecimiento in vitro}

La investigación se realizó en el Laboratorio de Biotecnología Forestal del Instituto de Investigación y Servicios Forestales (INISEFOR) de la Universidad Nacional (UNA), el material experimental fue donado por el proyecto Mejoramiento genético de Caoba (III fase) Universidad Nacional, INISEFOR.

Los clones utilizados fueron el número 33 y 80 , los cuales se mantuvieron en condiciones de invernadero a temperatura promedio $27^{\circ} \mathrm{C}, 60 \%$ de humedad relativa y tratados semanalmente con una mezcla de $2 \mathrm{~g} / \mathrm{L}$ de agimicyn/benlate y $50 \mathrm{mg} \mathrm{L}^{-1}$ de 6-Bencilaminopurina (6-BAP).Estos clones se seleccionaron porque presentaron un crecimiento juvenil superior (diámetro y altura), en los primeros dos años de plantados en un ensayo clonal en Guápiles, Limón, Costa Rica.
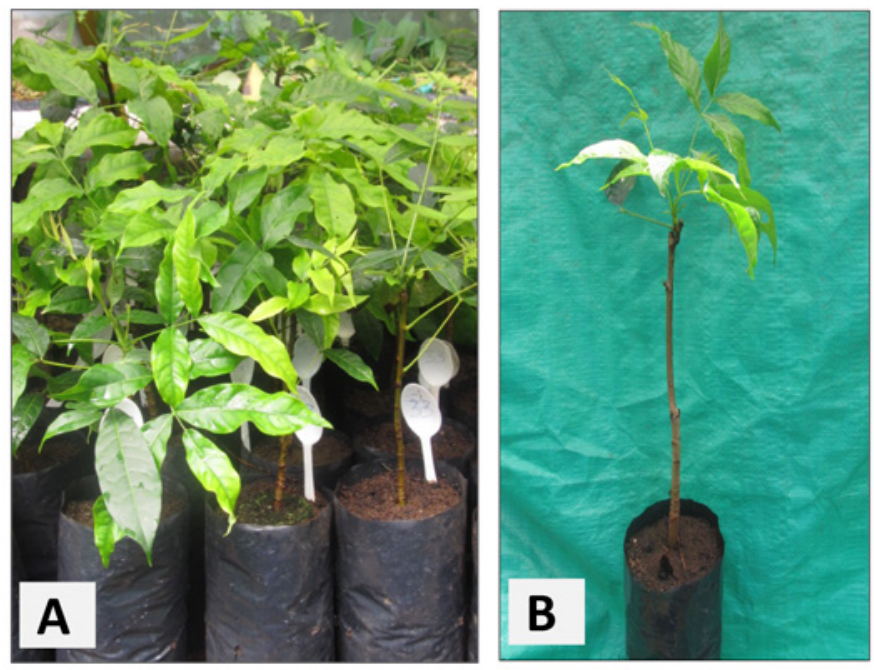

Figura 1. Material vegetal para el establecimiento in vitro de Swietenia macrophylla King. A) planta madre clon 33; B) planta madre clon 80 .

El material experimental a introducir en condiciones in vitro, consistió de segmentos nodales tomados de brotes axilares de plántulas mantenidas en condiciones de invernadero (Figura 1). Para la desinfección del material, se colectaron los segmentos nodales y del invernadero se trasladaron al laboratorio en una solución de 0,5 g/l de cisteína. Posteriormente, se mantuvieron durante 1 hora bajo el flujo de agua constante, seguido se sumergieron en una solución de agua y jabón líquido Antibacterial Bactex (Punto Rojo S.A.) al $1 \%$ por 10 min en agitación y se lavaron con ayuda de un cepillo suave para eliminar los contaminantes adheridos superficialmente, luego se enjuagaron con abundante agua. Finalmente, se evaluaron tres metodologías de desinfección para la introducción in vitro (Cuadro 1).

\begin{tabular}{|c|c|c|c|c|c|}
\hline 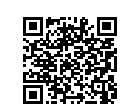 & (c) (i) (5) & $\underset{\text { AMBIENTALES }}{\Leftrightarrow}$ & $\frac{9 \%}{\text { euna }}$ & 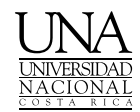 & 49 \\
\hline
\end{tabular}




\section{Revista de CIENCIAS AMBIENTALES Tropical Journal of Environmental Sciences}

Revista de Ciencias Ambientales (Trop J Environ Sci)

e-ISSN: 2215-3896

(Julio-Diciembre, 2019) . Vol 53(2): 47-59

DOI: https://doi.org/10.15359/rca.53-2.3

Open Access: www.revistas.una.ac.cr/ambientales e-mail: revista.ambientales@una.ac.cr Rojas-Vargas A. y Hine-Gómez A.

Cuadro 1. Tratamientos empleados para el establecimiento de una metodología de desinfección para nudos de Swietenia macrophylla King

\begin{tabular}{|c|c|c|c|}
\hline \multirow{2}{*}{ Pasos de desinfección } & \multicolumn{3}{|c|}{ Tratamientos $^{\star}$} \\
\hline & A & B & C \\
\hline $\begin{array}{l}\text { 1. Sumergir en una mezcla en agitación de hipoclorito de calcio } 15 \% \mathrm{Ca}(\mathrm{ClO}) 2 \text { i.a }+0.1 \% \text { de } \\
\text { tween } 80 \text { por } 20 \text { minutos. }\end{array}$ & $\sqrt{ }$ & & \\
\hline $\begin{array}{l}\text { 2. Sumergir en una solución de hipoclorito de sodio } 3,0 \%(\mathrm{NaClO} \text { i.a })+0.1 \% \text { de tween } 80 \\
\text { por } 5 \text { minutos sonicador }\end{array}$ & & $\sqrt{ }$ & \\
\hline $\begin{array}{l}\text { 3. Sumergir en una solución de hipoclorito de sodio } 3,0 \%(\mathrm{NaClO} \text { i.a })+0.1 \% \text { de tween } 80 \\
\text { por } 5 \text { minutos en bomba al vacío. }\end{array}$ & & & $\sqrt{ }$ \\
\hline 4. Cuatro lavados con agua destilada estéril en la cámara de flujo laminar de dos minutos. & $\sqrt{ }$ & $\sqrt{ }$ & $\sqrt{ }$ \\
\hline
\end{tabular}

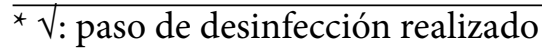

Los explantes se cultivaron en un medio de cultivo Murashige y Skoog (MS) (1962) a la mitad de su fuerza iónica, complementado con $3 \%$ de sacarosa, Agrimicin ${ }^{\circledast}(0.016 \mathrm{~g} / \mathrm{l})$ y Benlate ${ }^{\odot}$ (0.016 g/l ), solidificado con $8 \mathrm{gL}^{-1}$ de $\operatorname{Agar}^{\mathrm{TM}}$ (Sigma, St. Louis, MO, USA); el pH del medio se ajustó a 5.7 antes de la esterilización por autoclave $\left(21^{\circ} \mathrm{C}, 1.1 \mathrm{~kg} / \mathrm{cm}^{2}\right.$ presión, 25 minutos).El material cultivado se colocó en el cuarto de crecimiento a una temperatura de $25{ }^{\circ} \mathrm{C}$, con un fotoperíodo de 16 horas luz y $30 \mu \mathrm{mol} \mathrm{m}^{-2} \mathrm{~s}^{-1}$ de intensidad lumínica. La evaluación de la desinfección se realizó cada 5 días durante 30 días. Las variables evaluadas fueron las siguientes: porcentaje de nudos contaminados, porcentaje de explantes necrosados y porcentaje de explantes libres de contaminación. Se utilizó un diseño irrestricto al azar y las posibles diferencias entre las medias en los diferentes tratamientos de desinfección se determinaron mediante la prueba de rangos múltiples de Tukey $5 \%$, utilizando el programa estadístico InfoStat / versión profesional 1.1 (Di Rienzo et al., 2011).

\subsection{Identificación de contaminantes presentes en los cultivos in vitro del clon $\mathbf{3 3}$ y clon $\mathbf{8 0}$}

En el Laboratorio de Fitopatología de la Escuela de Ciencias Agrarias de la Universidad Nacional, se analizaron plantas in vitro de ambos clones. Los análisis realizados fueron: cultivo en PDA acidificado y PDA sin acidificar para el crecimiento de hongos y bacterias, tinción de gram, anaerobiosis, amarillamiento en YDC y fluorescencia en KB.

\subsection{Inducción de brotes a partir en segmentos nodales}

Se estudiaron cinco concentraciones de 6-BAP (Sigma, St. Louis, MO, USA): 0, 0.88, 1.33, 1.77 y $2.21 \mu \mathrm{M} \mathrm{L}^{-1}$.Como unidad experimental se consideró un segmento modal de $2 \mathrm{~cm}$ de longitud cultivado en un tubo de ensayo $(150 \mathrm{~mm}$ x $25 \mathrm{~mm})$ con $10 \mathrm{ml}$ de medio de cultivo MS (Murashige y Skoog, 1962), complementado con $3 \%$ de sacarosa y solidificado con 8 g. $\mathrm{L}^{-1}$ de

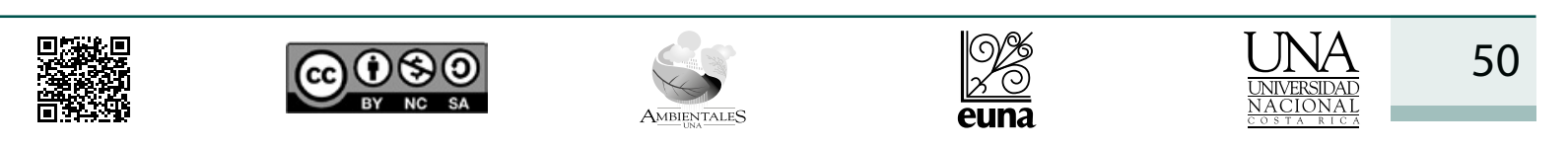




\section{Revista de CIENCIAS AMBIENTALES Tropical Journal of Environmental Sciences}

Revista de Ciencias Ambientales (Trop J Environ Sci)

e-ISSN: 2215-3896

(Julio-Diciembre, 2019) . Vol 53(2): 47-59

DOI: https://doi.org/10.15359/rca.53-2.3

Open Access: www.revistas.una.ac.cr/ambientales

e-mail: revista.ambientales@una.ac.cr Rojas-Vargas A. y Hine-Gómez A.

Agar. El pH del medio se ajustó a 5.7 antes de la esterilización por autoclave $\left(21^{\circ} \mathrm{C}, 1.1 \mathrm{~kg} / \mathrm{cm}^{2}\right.$ presión, 25 minutos). Se utilizaron 20 repeticiones por tratamiento. El material cultivado se colocó en el cuarto de crecimiento a una temperatura de $25^{\circ} \mathrm{C}$, con un fotoperíodo de 16 horas luz y $30 \mu \mathrm{mol} \mathrm{m} \mathrm{m}^{-2} \mathrm{~s}^{-1}$ e intensidad lumínica. La evaluación de la brotación se evaluó semanalmente por 30 días, durante 90 días consecutivos, con cambio de medio de cultivo cada 30 días. Se evaluó número de brotes nuevos por explante y en cada uno de los ensayos se utilizó un diseño completamente al azar con 20 nudos por tratamiento y las posibles diferencias entre las medias en los diferentes tratamientos se determinaron mediante la prueba de rangos múltiples de Tukey $5 \%$, utilizando el programa estadístico InfoStat / versión profesional 1.1 (Di Rienzo et al., 2011).

\section{3. Resultados y discusión}

\subsection{Establecimiento in vitro de clones superiores de caoba}

La primera etapa de un protocolo de propagación in vitro de una especie vegetal es establecer una desinfección exitosa del explante, que permita el crecimiento y desarrollo de una planta en condiciones de laboratorio libre de patógenos (George, 2008). En esta etapa es muy importante la calidad fitosanitaria de las plantas madres o plantas donantes, que deben estar en condiciones controladas, bajo un buen manejo y aplicación de productos que atenúen el efecto de los microorganismos contaminantes durante la etapa de establecimiento in vitro.

En el caso del clon 80 hubo presencia de contaminantes hongo o bacteria (Cuadro 2). Por lo general, esta contaminación microbiana se debe a que los explantes provienen de condiciones de invernadero; y aunque las plantas en el invernadero fueron tratadas con fungicida, bactericida y desinfectadas con hipoclorito de calcio y sodio no fue suficiente para eliminar por completo la presencia de contaminantes en el tejido vegetal.

En los tratamientos de desinfección utilizados, se observó diferencia significativa. El mejor tratamiento fue el A, que consistió de hipoclorito de calcio al $15 \% \mathrm{Ca}(\mathrm{ClO}) 2$ i.a con $0.1 \%$ de tween 80 por 20 minutos de exposición. Con este tratamiento se obtuvo un $55 \%$ de explantes libres de contaminación (Figura 2); mientras que con los tratamientos $\mathrm{B}$ y $\mathrm{C}$ se obtuvo presencia de algún tipo de contaminante (hongo o bacteria) o material necrosado. Este resultado es similar con lo reportado por Rodríguez et al., (2003), quienes obtuvieron los mejores resultados para el establecimiento in vitro de Caoba híbrida, utilizando hipoclorito de calcio con tiempos de 6 exposición de 10 o 15 minutos. Sin embargo, el resultado de la presente investigación es inferior al obtenido por Carranza et al., (2013), quienes lograron cerca de $90 \%$ de explanes libres de contaminación utilizando $15 \%$ de $\mathrm{Ca}(\mathrm{ClO}) 2$ por 20 minutos de exposición, pero con la diferencia que dichos autores utilizaron un baño con una solución de gentamicina de $20 \mathrm{mg} \mathrm{L-1}$ por 20 minutos en cámara de flujo laminar vertical, antes de colocarlos en el medio de cultivo para su establecimiento in vitro.

\begin{tabular}{|c|c|c|c|c|c|}
\hline 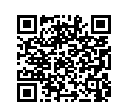 & (c) & $\underset{\text { AMBIENANALES }}{\infty}$ & $\frac{O \%}{20}$ & 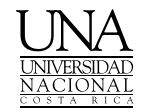 & 51 \\
\hline
\end{tabular}




\section{Revista de CIENCIAS AMBIENTALES Tropical Journal of Environmental Sciences}

Revista de Ciencias Ambientales (Trop J Environ Sci)

e-ISSN: 2215-3896

(Julio-Diciembre, 2019) . Vol 53(2): 47-59

DOI: https://doi.org/10.15359/rca.53-2.3

Open Access: www.revistas.una.ac.cr/ambientales

e-mail: revista.ambientales@una.ac.cr Rojas-Vargas A. y Hine-Gómez A.

Cuadro 2. Efecto del tipo de desinfectante en el establecimiento in vitro de explantes del clon 80 de Swietenia macrophylla King, luego de 16 días de cultivo

\begin{tabular}{cccc}
\hline Tratamientos & $\begin{array}{c}\text { Explantes libres de } \\
\text { contaminación (\%, E.E.) }\end{array}$ & $\begin{array}{c}\text { Explantes } \\
\text { necrosados (\%, E.E.) }\end{array}$ & $\begin{array}{c}\text { Explantes } \\
\text { contaminados (\%, } \\
\text { E.E.) }\end{array}$ \\
\hline A & $55 \pm 0.04 \mathrm{c}^{*}$ & $5 \pm 0.04 \mathrm{c}$ & $40 \pm 0.04 \mathrm{c}$ \\
B & $0 \pm 0.00 \mathrm{~b}$ & $10 \pm 0.05 \mathrm{~b}$ & $90 \pm 0.05 \mathrm{~b}$ \\
C & $0 \pm 0.00 \mathrm{a}$ & $0 \pm 0.00 \mathrm{a}$ & $100 \pm 0.00 \mathrm{a}$ \\
\hline
\end{tabular}

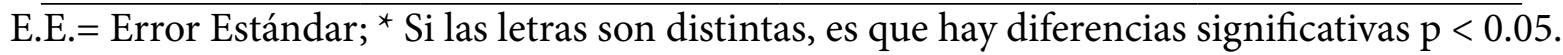
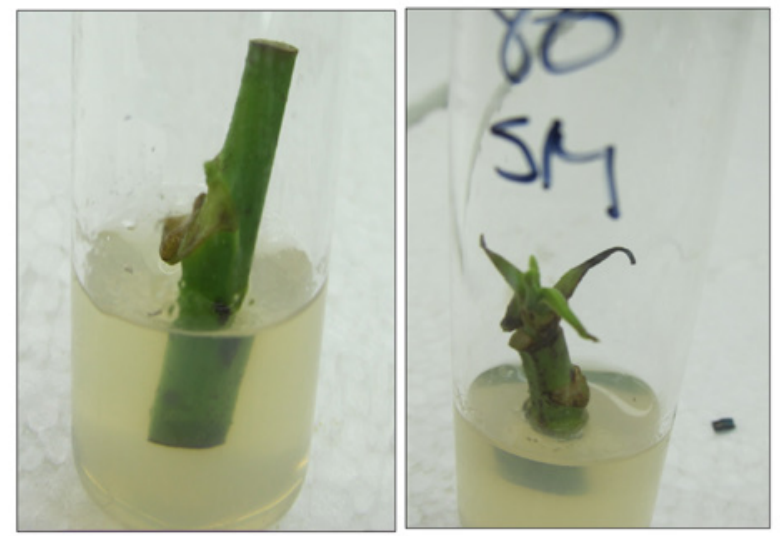

Figura 2. Establecimiento in vitro del clon 80 de caoba (Swietenia macrophylla King) después de 16 días en un medio de cultivo MS (1962) (Tratamiento A).

$\mathrm{Al}$ analizar el clon 33, se presentó el mismo resultado que en el clon 80 (Cuadro 3), el mayor número de explantes libres de contaminación se logró al utilizar al utilizar el hipoclorito de calcio. No obstante, da Costa Nunes et al., (2003), Mona (2012) y Soto et al., (2010) lograron establecer en condiciones in vitro explantes de Swietenia macrophylla y Cedrela salvadorensis (Meliaceae) respectivamente, utilizando hiplocorito de sodio en diferentes concentraciones; pero el explane utilizado fue semilla o segmentos de hojas. Dichos explanes presentan, características fisiológicas y genéticas diferentes a la de un segmento nodal.

George et al., (2008), recalcan que la condición fisiológica de la planta madre o donadora de los explantes para el establecimiento in vitro, tiene una influencia directa en el posterior comportamiento del cultivo. Esta explicación podría influir en la respuesta de cada clon, ya que el mayor número de explanes libres de contaminación se obtuvo con el mismo tratamiento (A). Por lo que, se podría atribuir a que las plantas madres provenían de un proceso de homogeneidad en las condiciones fitosanitarias. Además, no se presentó diferencia estadística significativa en los clones al utilizar la concentración de hipoclorito de calcio al $15 \%$ adicionado de $0.1 \%$ de

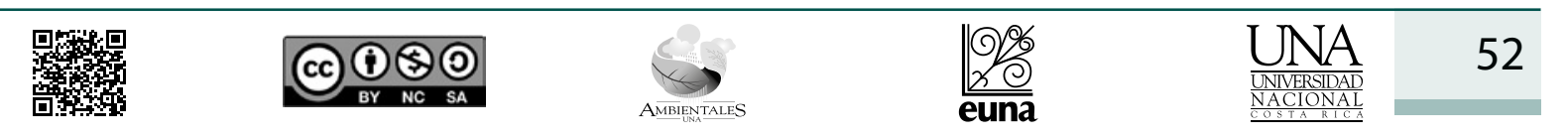




\section{Revista de CIENCIAS AMBIENTALES Tropical Journal of Environmental Sciences}

Revista de Ciencias Ambientales (Trop J Environ Sci) e-ISSN: $2215-3896$

(Julio-Diciembre, 2019) . Vol 53(2): 47-59 DOI: https://doi.org/10.15359/rca.53-2.3 Open Access: www.revistas.una.ac.cr/ambientales e-mail: revista.ambientales@una.ac.cr Rojas-Vargas A. y Hine-Gómez A.

Cuadro 3. Efecto del tipo de desinfectante en el establecimiento in vitro de explantes del clon 33 de Swietenia macrophylla King, luego de 16 días de cultivo

\begin{tabular}{cccc}
\hline Tratamientos & $\begin{array}{c}\text { Explantes libres de } \\
\text { contaminación (\%, E.E.) }\end{array}$ & $\begin{array}{c}\text { Explantes } \\
\text { necrosados (\%, } \\
\text { E.E.) }\end{array}$ & $\begin{array}{c}\text { Explantes } \\
\text { contaminados (\%, } \\
\text { E.E.) }\end{array}$ \\
B & $30 \pm 0.03 \mathrm{~b}$ & $0 \pm 0.03 \mathrm{~b}$ & $70 \pm 0.03 \mathrm{~b}$ \\
C & $0 \pm 0.00 \mathrm{a}$ & $15 \pm 0.04 \mathrm{a}$ & $85 \pm 0.04 \mathrm{a}$ \\
& $0 \pm 0.00 \mathrm{a}$ & $0 \pm 0.00 \mathrm{a}$ & $100 \pm 0.00 \mathrm{a}$ \\
\hline
\end{tabular}

E.E.= Error Estándar; ${ }^{\star}$ Si las letras son distintas, es que hay diferencias significativas $\mathrm{p}<0.05$.

tween 80 con un tiempo de exposición de 20 minutos. La misma permitió el establecimiento in vitro de ambos clones. (Figura 2 y 3), donde se puede observar el desarrollo de los meristemas laterales y apical que permitirán el crecimiento de una planta. Por lo que, se podría recomendar como guía para la introducción in vitro de rebrotes de otras especies forestales del trópico pertenecientes a un programa de mejoramiento genético forestal; cuando las plantas madres provienen de un jardín clon y se encuentran sembradas en tierra como sustrato.
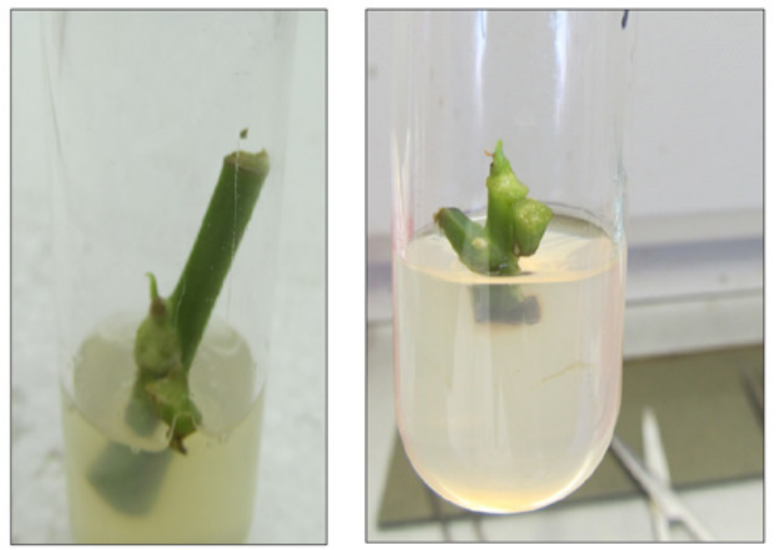

Figura 3. Establecimiento in vitro del clon 33 de caoba (Swietenia macrophylla King) después de 16 días en un medio de cultivo MS (1962). (Tratamiento A).

Por otra parte, la identificación de contaminantes en la etapa de establecimiento es esencial para reducir el porcentaje de contaminación, así como para conocer métodos como la aplicación de productos que se podrían aplicar a las plantas madres para contribuir al éxito del establecimiento in vitro. Los resultados de los análisis de fitopatología detectaron en el clon 80 la presencia de colonias del hongo Penicillium sp, de la bacteria Pseudomonas sp, así como colonias de levadura. Por su parte, en plantas in vitro del clon 33 se detectó la presencia de tres

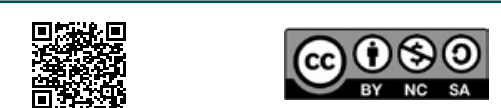




\section{Revista de CIENCIAS AMBIENTALES Tropical Journal of Environmental Sciences}

Revista de Ciencias Ambientales (Trop J Environ Sci)

e-ISSN: 2215-3896

(Julio-Diciembre, 2019) . Vol 53(2): 47-59

DOI: https://doi.org/10.15359/rca.53-2.3

Open Access: www.revistas.una.ac.cr/ambientales

e-mail: revista.ambientales@una.ac.cr Rojas-Vargas A. y Hine-Gómez A.

colonias de la bacteria Pseudomonas sp que se sugiere podría ser endofítica o estar latente en el tejido vegetal. Acosta 2009 y Alvarado 1998, explican que, por lo general, en el proceso de cultivo in vitro, la contaminación interna de los explantes, constituye uno de los problemas fundamentales para su establecimiento y posterior multiplicación. Lo anterior, se puede deber a que los microorganismos asociados a los tejidos de las plantas in vivo tienen la capacidad permanecer latentes en el interior de las células, los espacios intercelulares o los haces conductores y quedar protegidos de los agentes químicos utilizados en el proceso de desinfección, resultado que se presentó en los tratamientos B y C. Además, estos microorganismos no son deseados en el cultivo in vitro ya que podrían interferir en la fisiología y morfología normal de la planta, afectando el protocolo de reproducción del cultivo (Vásquez et al., 2014).

\subsection{Inducción de brotes en segmentos nodales}

De acuerdo con el Cuadro 4 el mayor número promedio de brotes por segmento nodal fue de 1.0. En en el clon 80 en todas las concentraciones se presentó brotación del segmento nodal. Sin embargo, los explantes respondieron igual a la inducción de brotes en el medio de cultivo que no tenía adición de citoquininas; pero la diferencia se presentó en el crecimiento de los brotes. En la concentración de $0,88 \mu \mathrm{M} \mathrm{L}^{-1}$ se observó un mayor desarrollo del brote y hojas (Figura 4b).

Cuadro 4. Efecto de diferentes concentraciones de 6-BAP sobre la inducción de brotes en nudos de clon 80 y 33 de Swietenia macrophylla establecidos en condiciones in vitro, luego de 90 días de cultivo

\begin{tabular}{lllll}
\hline $\begin{array}{l}\text { Tratamientos } \\
\text { 6-BAP } \mu \mathrm{M} \mathrm{L}^{-1}\end{array}$ & $\begin{array}{l}\text { Porcentaje explanes } \\
\text { brotados }\end{array}$ & \multicolumn{2}{l}{ No brote/explante } \\
\hline & Clon 80 & Clon 33 & Clon 80 & Clon 33 \\
\hline 0.00 & 30 & 0 & 1 & 0 \\
0.44 & 25 & 15 & 1 & 1 \\
0.88 & 30 & 50 & 1 & 1 \\
1.33 & 20 & 40 & 1 & 1 \\
1.77 & 5 & 0 & 1 & 0 \\
2.21 & 15 & 0 & 1 & 0 \\
\hline
\end{tabular}

En el caso del clon 33 en las concentraciones de $1.77 \mu \mathrm{M} \mathrm{L}^{-1} \mathrm{y} 2.21 \mu \mathrm{M} \mathrm{L}^{-1}$ de 6-BAP, al igual que en el tratamiento testigo no se presentó brotación en el segmento nodal. En la concentración de $0.44 \mu \mathrm{M} \mathrm{L}^{-1}$ se observó el mejor desarrollo del brote (Figura 4a).

\begin{tabular}{|c|c|c|c|c|c|}
\hline 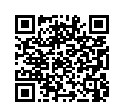 & (c) (i) (-) & $\overbrace{\text { AMBENETIES }}$ & $\frac{9 \%}{\text { euna }}$ & 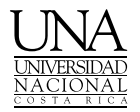 & 54 \\
\hline
\end{tabular}




\section{Revista de CIENCIAS AMBIENTALES Tropical Journal of Environmental Sciences}

Revista de Ciencias Ambientales (Trop J Environ Sci) e-ISSN: $2215-3896$

(Julio-Diciembre, 2019) . Vol 53(2): 47-59 DOI: https://doi.org/10.15359/rca.53-2.3 Open Access: www.revistas.una.ac.cr/ambientales e-mail: revista.ambientales@una.ac.cr Rojas-Vargas A. y Hine-Gómez A.
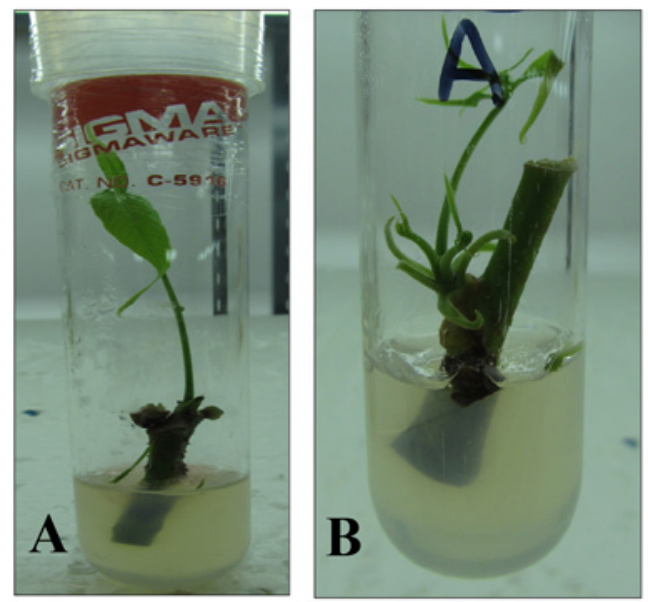

Figura 4. Brote de caoba (Swieteniamacrophylla King) inducido con $0.88 \mu \mathrm{M} \mathrm{L}^{-1}$ de 6-BAP. A) Clon 80; B) Clon 33.

George et al., (2008) han empleado en el establecimiento de especies leñosas, diferentes tipos de citoquininas. Las citoquininas son producidas en las zonas de crecimiento, como los meristemos y en la punta de las raíces y se traslocan muy poco o casi nada en la planta (Taiz y Zieger, 2006). Por lo general, la citoquinina más utilizada es el 6-BAP, se aplica en bajas concentraciones y estimula las yemas apicales y terminales en la etapa de mciropropgación. Además, promueve no sólo la división celular sino también la brotación y elongación de las yemas (Collado et al., 2004).

Investigaciones realizadas en Meliaceaes como Cedrela salvadorensis utilizaron el (6-BAP) para la brotación de segmentos nodales, obteniendo diferencia significativa entre las concentraciones utilizadas (Soto et al., 2010). Además, algunos autores utilizan una relación auxina/ citoquininas para promover el crecimiento y la morfogénesis in vitro, cuando la relación en el medio de cultivo es baja se favorece la formación de tallos, pero en caso contrario favorece el enraizamiento (Buchanan et al., 2000, Persinova et al., 2008).

Carranza et al., (2013) y Mona (2012) utilizaron el 6-BAP solo o combinado con 2ip para la etapa de multiplicación de segmento nodales de Caoba. Mona (2012), obtuvo el mejor coeficiente de multiplicación en los medios que contenían ambos reguladores de crecimiento, pero los brotes presentaron hiperhidricidad. El autor recalca, que a pesar de tener mayor número de brotes en los tratamientos con ambos reguladores del crecimiento la calidad del brote es mejor cuando se utiliza el 6-BAP; resultado que coincide con el obtenido en la presente investigación. Lo anterior, se podría deber a que algunos autores consideran que la citoquinina 6-BAP tiene mayor respuesta comparada con otras hormonas como la kinetina, TDZ y 2 -isopenteniladenina (2iP), ya que promueve la formación de un mayor número de brotes y son de mayor longitud, lo que se traduce en un mayor coeficiente de multiplicación (Arab et al., 2014; Pérez et al., 2002).

\begin{tabular}{|c|c|}
\hline 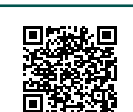 & (c) (i) (-) (-) \\
\hline
\end{tabular}




\section{Revista de CIENCIAS AMBIENTALES Tropical Journal of Environmental Sciences}

Revista de Ciencias Ambientales (Trop J Environ Sci)

e-ISSN: 2215-3896

(Julio-Diciembre, 2019) . Vol 53(2): 47-59

DOI: https://doi.org/10.15359/rca.53-2.3

Open Access: www.revistas.una.ac.cr/ambientales

e-mail: revista.ambientales@una.ac.cr Rojas-Vargas A. y Hine-Gómez A.

Además, el 6-BAP es metabolizado por los tejidos mucho más fácil que el resto de los reguladores sintéticos y es capaz de inducir la producción de otras hormonas naturales como la Zeatina (Malik et al., 2005).

Por otra parte, Rodríguez et al., (2003) obtuvo mayor brotación en concentraciones superiores de $1 \mathrm{mg} / \mathrm{L}$ de 6-BAP, pero la elongación del brote no fue el mejor. Por lo tanto, concluye que en entre $0.50 \mathrm{mg} / \mathrm{L}$ y $1 \mathrm{mg} / \mathrm{L}$ de 6-BAP se complementan los valores óptimos de multiplicación sin tener una incidencia directa en la elongación; resultado que coincide al obtenido en la presente investigación. Por lo anterior, se podría sugerir que, en caoba, utilizando este tipo de explante el efecto de las citoquininas solas o en combinación, no logran más de $0.33-0.10 \%$ de brotación.

$\mathrm{Al}$ evaluar la respuesta al comportamiento de morfogenesis in vitro que se presentó en el porcentaje de explanes brotados y la inducción de nuevos brotes en ambos clones. La diferencia se podría atribuir a los factores que argumentan los autores Azofeifa et al., (2009), quienes mencionan que los requerimientos de citoquinina en las plantas in vitro son extremadamente variables y las respuestas a la inducción de brotes dependen del contenido endógeno de cada especie y del estado fisiológico y tipo de explante utilizado. El explante utilizado en la presente investigación fue el mismo, por lo que presentó características fisiológicas similares. Sin embargo, entre individuos de la misma se podría presentar una variación debida al genotipo. En esta investigación eran dos genotipos que podrían tener contenidos endógenos de citoquininas diferentes y por ende la brotación no debería ser la misma.

Barbón et al. (2006) explican que caoba es difícil de propagar mediante el cultivo de tejidos y hasta la fecha no existe un sistema de regeneración de plantas vía organogénesis repetible para esta especie, debido básicamente a problemas de contaminación microbiana, oxidación fenólica y muerte de tejidos en la fase de establecimiento de los explantes in vitro. Por tanto, los presentes resultados son válidos debido a que utilizó clones de la especie que pertenecen a un programa de mejoramiento genético y se logró establecer una metodología de desinfección, un medio de cultivo y un tratamiento de multiplicación de segmentos nodales.

\section{Conclusiones}

Los resultados logrados para los clones de Swietenia macrophylla evidencian el comportamiento recalcitrante de estas especies en condiciones in vitro y la necesidad de realizar más estudios que permitan el establecimiento de un sistema de regeneración in vitro eficiente para esta especie. Sin embargo, su establecimiento en condiciones in vitro fue posible al utilizar hipoclorito de calcio para el establecimiento de segmentos nodales, y el uso de 6-BAP para inducir la formación de nuevos brotes in vitro. Es recomendable estudiar otras metodologías de multiplicación que permita la propagación del material ya establecido.

\begin{tabular}{|c|c|c|}
\hline 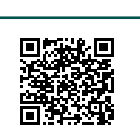 & (c) ${ }_{\mathrm{BY}}(\mathbf{\mathrm { NC }}) \mathrm{SA}$ & 56 \\
\hline
\end{tabular}




\section{Revista de CIENCIAS AMBIENTALES Tropical Journal of Environmental Sciences}

Revista de Ciencias Ambientales (Trop J Environ Sci) e-ISSN: 2215-3896

(Julio-Diciembre, 2019) . Vol 53(2): 47-59 DOI: https://doi.org/10.15359/rca.53-2.3

Open Access: www.revistas.una.ac.cr/ambientales e-mail: revista.ambientales@una.ac.cr Rojas-Vargas A. y Hine-Gómez A.

\section{Agradecimientos}

Al señor Eugenio Corea, encargado del proyecto "Mejoramiento genético de Caoba. (III fase)" del Instituto de Investigación y Servicios Forestales (INISEFOR), Universidad Nacional, por facilitar el material experimental utilizado en esta investigación. A la Revista y a las personas revisoras anónimas por los valiosos aportes al escrito.

\section{Referencias}

Acosta, M., Alvarado, Y., Cruz, M., Leiva, M., Sánchez, C., Berkis, G., Quiala, E., Chávez, M., Jiménez, F., La O M, Barbón, R., Collado, R., Rodríguez, M., De Feria, M., Borroto, I. y Pérez, M. (2009). Micobiota de plantas donadoras y hongos filamentosos contaminantes del establecimiento in vitro de cinco especies forestales. Biotecnología Vegetal, 9 (2), 99-103.

Alvarado, Y. (1998). Contaminación microbiana en el cultivo in vitro de plantas. In Pérez, J. Ed. Propagación y mejora genética de plantas por biotecnología. Cuba: Instituto de Biotecnología de Plantas. https://doi.org/10.14195/978-989-26-0404-6

Arab, M; Yadollahi, A: Shojaeiyan, A: Shokri, S; Ghojah, S. Effectsof nutrient media, different cytokinin types and their concentrations on in vitro multiplication of G X N15 (hybrid of almond peach) vegetative rootstock. (2014). Journal of Genetic Engineering and Biotechnology, 12:81-87. https://doi.org/10.1016/j.jgeb.2014.10.001

Azofeifa, J., Rojas, A., y Hine, A. (2009). Optimización del proceso de enraizamineto y aclimatización de vitroplantas de Swietenia macrophylla King (Orden: Meliacea). Tecnología en Marcha, 22 (3), 34-41.

Barbón, R., Agramonte, D., Collado, R., Terry, F., Quiala, E., y Odalys, M. (2006). Taller Leñosas. Avances en el cultivo in vitro de especies leñoas y foresatles en el Instituto de Biotecnología de Plantas. Biotecnología Vegetal, 6 (2), 103-117.

Buchanan, B., Gruissem, W. y Jones, R. (2000). Biochemistry \& molecular biology of plants. Estados Unidos. Editorial Rockville, Md.: American Society of Plant Physiologists.

Carranza, M., Reyees, H., Mora, W., Cevallos, O., Escobar, A., Cadme, M., Nieto, J. y Morante, J. (2013). Propagación in vitro de Swietenia macrophylla King (Caoba). Ciencias y Tecnología, 6(2), 1-8. https://doi.org/10.18779/cyt.v6i2.177

Collado, R., Barbón, R., Agramonte, D., Jiménez, F., Pérez, M., Gutiérrez, O., y Ramírez, D. (2004). Establecimiento in vitro de ápices y segmentos nodales de Swietenia macrophylla King. Biotecnología Vegetal, 4(3), 143-146.

Convención sobre el comercio internacional de especies amenazadas de fauna y flora silvestres. (2017). Apéndices I, II y III. Recuperado de https://cites.org/sites/default/files/esp/ app/2017/S-Appendices-2017-10-04.pdf.

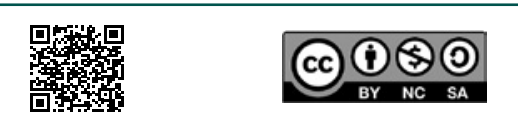

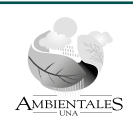




\section{Revista de CIENCIAS AMBIENTALES Tropical Journal of Environmental Sciences}

Revista de Ciencias Ambientales (Trop J Environ Sci) e-ISSN: 2215-3896

(Julio-Diciembre, 2019) . Vol 53(2): 47-59 DOI: https://doi.org/10.15359/rca.53-2.3 Open Access: www.revistas.una.ac.cr/ambientales e-mail: revista.ambientales@una.ac.cr Rojas-Vargas A. y Hine-Gómez A.

Corea, E. (2012). Proyecto Mejoramiento genético de Caoba. (III fase). Costa Rica: Universidad Nacional.

da Costa Nunes, E., Benson, E., Oltramari, A., Araujo, S., Moser, M., y Vaina, M. (2003). In vitro conservation of Cedrela fissilis Vellozo (Meliaceae), a native tree of the Brazilian Atlantic Forest. Biodiversity and Conservation, 12, 837-848. https://doi.org/10.1023/a:1022492226341

Di Rienzo, J., Casanoves, F., Balzarini, M., Gonzalez, L., Tablada, M. y Robledo, C. (2011). InfoStat versión 2011. Argentina: Universidad Nacional de Córdoba. Recuperado de: http://www. infostat.com.ar.

Estrada, A., Rodríguez, A., Sánchez, y J. (2005). Evaluación y categorización del estado de la conservación de plantas en Costa Rica. Recuperado de http.//documentación.sire.for.go.cr/ archivo/CBN/categorización/categorizacion_especies.pdf

George, E. (2008). Plant Tissue Culture Procedure-Background. In George, E; Hall, M; Jan de Klerk, G. eds. Plant Propagation by tissue culture. 3 ed. Holanda: Editorial Springer. https:// doi.org/10.1007/978-1-4020-5005-3_1

Malik S. K., R. Chaundhury and R. K. Kalia. (2005). Rapid in vitro multiplication and conservation of Garcinia indica: a tropical medicinal tree species. Scientia Horticulturae, 106:539-553.

Martínez, R., Azpiroz, H., Rodríguez, J., Cetina, V., Gutiérrez, M. (2003). Aplicación de la biotecnología en los recursos genéticos forestales. Revista Chapingo. Serie ciencias forestales y del ambiente, 49(1), 17-34. https://doi.org/10.5154/r.rchscfa.crossmark-policy

Maruyama, E., Ishii, K., Kinoshita, I., Ohba, K., y Saito, A. (1997) Micropropagation of Guazuma crinita Mart. by root and petiole culture. In vitro Cellular Developmental. Biology Plant, 33,131-135. https://doi.org/10.1007/s11627-997-0011-0

Mona, A. (2012). In Vitro Propagation of Swietenia macrophylla King. Research Journal of Agriculture and Biological Sciences, 8(2), 282-287. https://doi.org/10.1016/j.scienta.2005.05.002

Murashige, T., Skoog, F.(1962). A revised medium for rapid growth and bioassays with tobacco tissue cultures. Physiolgia Plantarum, 15, 473-497.

Pérez, E: Dávila, C. (2002). In vitro propagation of Pelecyphora aselliformis Ehrenberg and P. strobiliformis Werdermann (Cactaceae). In vitro Cell. Dev. Biol.-Plant 38, 73-78. https://doi. org/10.1079/ivp2001248

Pernisova, M., Klıma, P., Horak, J., Valkova, M., Malbeck, J., Soucek, P., Reichman, P., Hoyerova, K., Dubova, J., Friml, J., Zazímalova, E., Hejatkoa, J. (2009). Cytokinins modulate auxin-induced organogenesis in plants via regulation of the auxin efflux. Proc Natl Acad Sci, 106: 3609-3614. https://doi.org/10.1073/pnas.0811539106

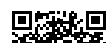




\section{Revista de CIENCIAS AMBIENTALES Tropical Journal of Environmental Sciences}
Revista de Ciencias Ambientales (Trop J Environ Sci) e-ISSN: 2215-3896
(Julio-Diciembre, 2019) . Vol 53(2): 47-59 DOI: https://doi.org/10.15359/rca.53-2.3 Open Access: www.revistas.una.ac.cr/ambientales e-mail: revista.ambientales@una.ac.cr Rojas-Vargas A. y Hine-Gómez A.

Rodríguez, R., Daquinta, M., Capote, I., Pina, D., Lezcano, Y., y González, L. (2003). Nuevos aportes a la micropropagación de Swietenia macrophylla X Swietenia mahogani (CAOBA HÍBRIDA) y Cedrela odorata (CEDRO). Cultivos Tropicales, 24 (3), 23-27. https://doi. $\operatorname{org} / 10.24841 /$ fa.v22i1-2.45

Schottz, E., Filho, A., Tracz, A., Luciana, L., Ribas, F., y Quoirin, M. (2007). In vitro multiplication of Swietenia macrophylla KING (MELIACEAE) from juvenile shoots. Ciência Florestal, 17 (2), 109-117. https://doi.org/10.5902/198050981942

Skoog, F. (1962). A revised medium for rapid growth and bioassays with tobacco tissue cultures. Physiolgia Plantarum, 15, 473-497.https://doi.org/10.1016/j.scienta.2005.05.002

Soto, B., Valverde, L., Rojas, A., y Hine, A. (2010). Establecimiento in vitro de Cedrela salvadorensis Standl. Tecnología en Marcha, 23 (4), 66-73.

Taiz, L. y Zeiger, E. (2006). Plant Physiology. 4ta ed. Sinauer Associates, Inc., Sunderland.

Vázquez, S., Larrañaga, N., Uberhuaga, E., Braga, E. y Ruíz, C. (2014). Bacterial contamination of in vitro plant cultures: confounding effects on somaclonal variation and detection of contamination in plant tissues. Plant Cell Organ Culture, 119, 533-541. https://doi.org/10.1007/ s11240-014-0553-X

Wadsworth, F. (2000). Producción forestal para América Tropical. Estados Unidos: USDA.

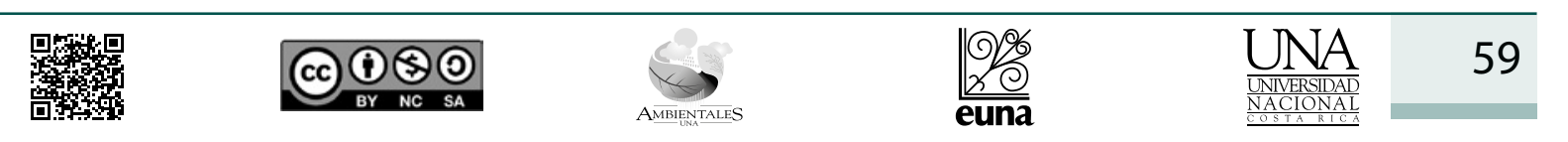

